\title{
AC 2012-3217: THE USE OF A PROJECT CIRCUIT IN THE TEACHING OF A BASIC ELECTRIC CIRCUITS COURSE
}

\section{Prof. James P Becker, Montana State University}

James Becker is an Associate Professor of electrical and computer engineering at Montana State University. His professional interests include microwave circuits, radio frequency electronics, nanoelectronics, pedagogical research, and distance education. He is a 2004 recipient of the NSF CAREER award.

\section{Dr. Carolyn Plumb, Montana State University}

Carolyn Plumb is the Director of Educational Innovation and Strategic Projects in the College of Engineering at Montana State University (MSU). She works on various curriculum and instruction projects including instructional development for faculty and graduate students. She also serves as the college's assessment and evaluation specialist, currently planning and implementing evaluation for several programs,

\section{Richard A. Revia, Montana State University}




\title{
The Use of a Project Circuit in the Teaching of a Basic Electric Circuits Course
}

\begin{abstract}
To better motivate the study of basic electric circuit analysis and to encourage a deep learning approach among the sophomore electrical engineering students taking the course, the implementation of a "project circuit" was carried out in the Fall 2011 offering of EELE 201 at Montana State University. The project circuit, a photoplethysmograph (PPG) circuit used to monitor a person's pulse, was chosen to demonstrate a compelling circuit whose design requires a student to have strong command of key topics from the course. For example, to understand the operation of the PPG circuit and to make reasonable design choices in implementing it, students must be comfortable in making basic voltage, current and power calculations for this batteryoperated device; they must be able to handle dependent sources calculations; identify and design basic operational amplifier (op amp) circuits; appreciate the importance of static offsets in op amps; develop Thévenin equivalent circuits; and carry out first-order circuit calculations. Naturally, students must also demonstrate skill in a laboratory setting as they put together and debug their circuits. So as to help the typical student through the relatively complex considerations in designing the project circuit, several standard lecture sessions were converted into active-learning group work. These activities were spread out over the semester and in many cases the activities amounted to pre-lab exercises including studying component datasheets and speculating on the impact of component specifications on circuit function. The lab activities were made to require students to tackle open-ended problems and fashioned using inquiry-based techniques.
\end{abstract}

The initial implementation was assessed in terms of student performance on essay type exams crafted to probe deeper knowledge of the course material, student mastery of standard learning outcomes as evidenced by their scores on more typical calculation-type exams, student surveys, and class observations made by an evaluation expert. Prior to the implementation of the project circuit materials in the course, baseline data were collected to provide a means to determine the impact of the project circuits on student learning. This paper provides details regarding the materials and activities developed around the project circuit as well as assessment tools, evaluation methods and results in comparing the initial implementation of the project circuit materials to an offering of the course prior to the intervention. Based on the assessment of the initial deployment of the project circuit materials, revision of both the in-class prelab activities and elements of the lab explorations are underway in an attempt to enhance the typical student's ability to connect and apply the concepts learned in class to the project circuit.

\section{Introduction}

Students enrolled in the Electrical and Computer Engineering Department at Montana State University are required to take a two-credit introductory course, EELE 101 - Introduction To Electrical Fundamentals Lab, in which they are first introduced to some of the basic topics and terminology of electrical and computer engineering. The class meets once a week for 50 minutes of lecture and once a week for an hour and 50 minutes in the lab. The sole pre-requisite for the 
course is pre-calculus, and the course is designed more to inspire interest among students for electrical and computer engineering while the students concurrently take the typical battery of math and science courses than to provide a rigorous introduction to the discipline. Details regarding the course have been published [1]. This introductory course is then followed by two required four-credit circuit analysis courses and a required four-credit electronics course. The focus of this paper is on the first of the two required circuit courses EELE 201 Circuits 1. EELE 201 is a standard introductory circuits course, meeting three times a week for 50 minute lectures and once per week for one hour and 50 minutes in the lab. A standard textbook is used in the class [2], complemented in the Fall 2011 offering with a "Project Circuit Workbook." Table I provides an overview of the topics/concepts covered in the course. Noticeably absent when compared to other introductory circuits courses is the study of the complete response of secondorder circuits, which is deferred to Circuits 2 at Montana State University. The study of secondorder circuits is delayed so as to allow students to have completed their required differential equations course prior to working with second-order differential equations. The math prerequisite for EELE 201 is calculus 2.

Table I: Course Topics for EELE 201

\begin{tabular}{|l|}
\hline Current, voltage, power and energy \\
\hline Linear versus nonlinear models \\
\hline Basic circuit elements including resistors, capacitors, inductors \\
\hline Independent and dependent sources \\
\hline Voltage and current measurement concepts \\
\hline Kirchhoff's Laws \\
\hline Series and parallel resistor combinations \\
\hline Voltage divider and current divider formulas \\
\hline Node voltage analysis \\
\hline Mesh current analysis \\
\hline Source transformations \\
\hline Superposition \\
\hline Thévenin and Norton equivalent circuits \\
\hline Maximum power transfer theorem \\
\hline Operational amplifier basics: the ideal op amp, standard configurations \\
\hline Operational amplifier non-idealities including finite gain and static offsets \\
\hline Energy storage in capacitors and inductors \\
\hline The complete response of first-order RC and RL circuits \\
\hline Sequential switching in first-order circuits \\
\hline Sinusoidal steady-state analysis \\
\hline AC steady-state power: instantaneous, average and complex power, power factor \\
\hline Coupled inductors and the ideal transformer \\
\hline
\end{tabular}

Based on informal feedback from students and instructor observations of students, both in the classroom and lab, it has become apparent to the instructor that a significant number of students taking the course find the material to be dry. Learning important concepts from circuit analysis such as superposition and the creation of Thévenin and Norton equivalents fails to inspire the typical student or so it seems. Those who excel in the course likely take it for granted that the material will be of some use later on in their studies and careers. A quick glance at many circuits 
textbooks suggests that authors and publishers are aware of the importance of providing motivation for the material. In many cases, textbooks use "design problems" near the end of a given chapter in an attempt to connect concept to application. The idea for the project circuit came about as a means to address the connection of concept to application issue in a very significant way through detailed design projects that students would carry out over a good portion of the semester. While the lab experiments that have been in use in EELE 201 provide fine examples of concepts, they did not do much more than reinforce a concept. For example, in one lab students were required to assemble a simple circuit that contained two voltage sources. Students were to take voltage and current measures on the circuit and then assemble and test the circuit with the two sources acting independently. By comparing the measured results of the combined circuit with the two circuits with a single source, students could verify superposition of voltage and current in a simple linear circuit. The goal of the project circuit concept is not so much to allow students to verify a concept, but rather to apply a concept to design or analyze a more complex circuit with compelling function.

\section{The PPG Circuit as Related to EELE 201}

Prior to beginning the development of the project circuits, the instructor attempted to determine student interest in the general concept of a project circuit and surveyed students in Circuits 1 to determine which application areas they found interesting. Based on survey results, applications in alternative energy, audio electronics and medical devices seemed most popular. To date, materials for two project circuits have been created, though for reasons to be explained, only one project circuit was deployed in the Fall 2011 offering of EELE 201. The deployed circuit, a photoplethysmograph (PPG) circuit, can be used to monitor an individual's pulse. As suggested in Figure 1, the EELE 201 PPG circuit consists of a light-emitting diode (LED), a phototransistor (PT), one or more operational amplifiers as well as several resistors, a single capacitor and an energy source such as a bench-top DC supply or a 9V battery for which the PPG is designed. In short, radiation emitted from the LED travels through a finger placed between the LED and the $\mathrm{PT}$. The radiation intensity received by the PT is modulated by the blood surges through the arteries serving the finger, creating a modulated photocurrent in the PT. The photocurrent is converted to a voltage using resistor $\mathrm{R}_{2}$; this voltage may be observed with an oscilloscope. A gain stage is included in the PPG circuit to boost the voltage such that it can drive an audible indicator that sounds with each pulse. Figure 2 shows representative PPG signals captured with an oscilloscope at the output of the PT (its collector) and the output of the entire PPG circuit. Analyzing a circuit of the complexity of that shown in Figure 1 would likely be extremely daunting to a student completing a typical introductory circuits course. By the end of the course, could a typical student break down such a circuit into its constituent parts to aid in its analysis? Could a typical student make intelligent choices for component values when weighing issues such as battery life, signal swing and operational amplifier offsets? Could a typical student assemble, debug and successfully demonstrate the proper operation of the circuit both through observation of the PPG waveform at the output and through the periodic beeping of a piezoelectric audible indicator connected to the circuit's output? Would the typical student feel the effort necessary to complete the project circuit worthwhile? These are questions that are to be answered and it is important to note that these questions are framed in terms of the typical student, not the top students. 


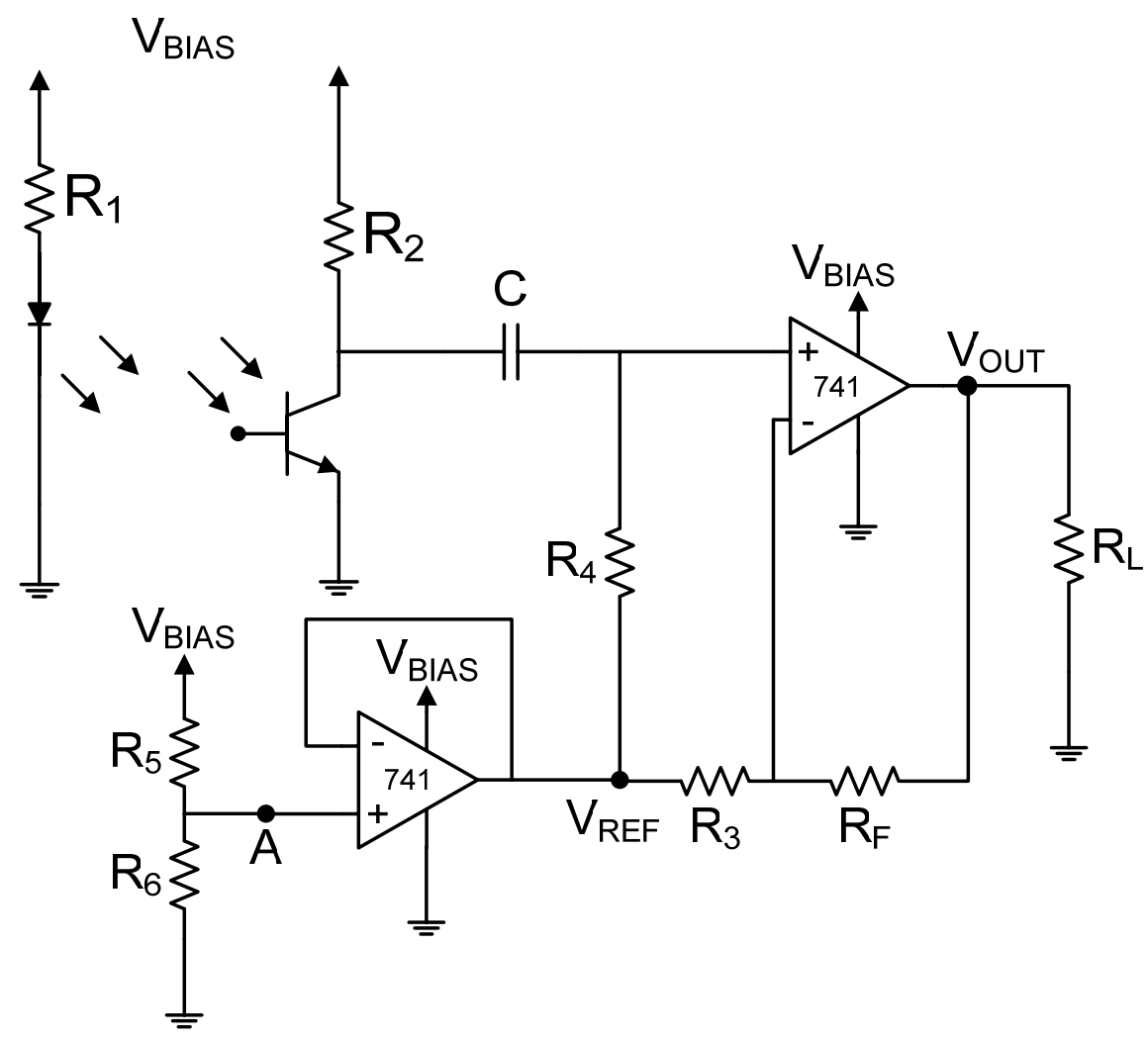

Figure 1: An example schematic diagram of a PPG circuit. Over the course of the semester students study the operation of the circuit and build two versions of this battery-operated circuit used to monitor an individual's pulse.

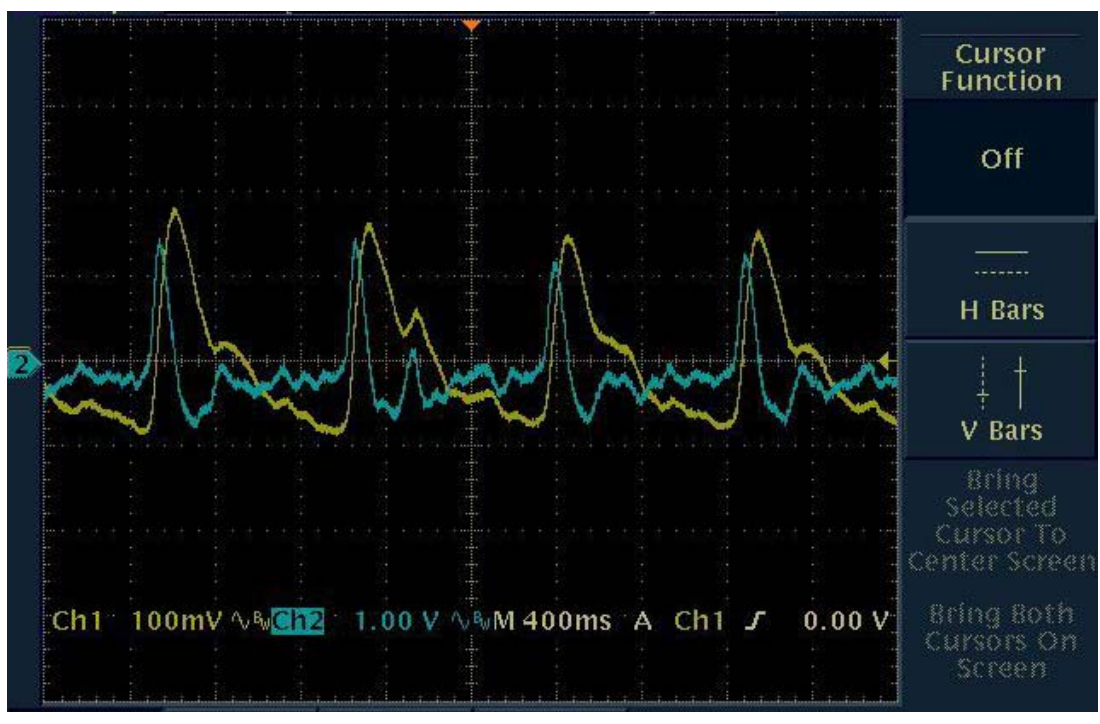

Figure 2: An example PPG waveform at both the phototransistor's collector (Yellow) and at the circuit's output (Blue). The voltage at the phototransistor's collector is typically on the order of 100 's $m V$. The noninverting operational amplifier is used to raise the PPG signal to a couple of volts to trigger the audible indicator placed at the circuit's output node. 
Table II attempts to concisely capture the connections between the PPG circuit and the standard course concepts. The two circuit elements of the PPG circuit that were not discussed in EELE 201 prior to the introduction of the project circuit are the LED and the PT and thus require additional discussion as to how their introduction into the course may be justified. One of the concepts discussed in the course is the modeling of linear and nonlinear elements. Prior to the introduction of the PPG project circuit, the course instructor would contrast the current-voltage relationship between a resistor and that of a diode to demonstrate linear versus non-linear behavior. In EELE 101, the introductory course noted previously, students have the opportunity in lab to use both a standard diode and an LED, so students beginning EELE 201 should have some familiarity with a diode. In the Fall of 2011, students completed activities related to the LED and $\mathrm{R}_{1}$ circuit loop both through in-class pre-lab activities and as part of PPG Lab 1 -- PPG Light Emitting Diode and Phototransistor Biasing Investigation.

During the pre-lab exercises students are asked, among other tasks, to use the ideal diode equation to calculate the necessary voltage drop across an LED to achieve $20 \mathrm{~mA}$ of current through the LED and to calculate the range of current values if the voltage drop across the diode were to change by $\pm 5 \%$ around the nominal value. Students then analyze a series circuit consisting of a voltage source, the same LED and a resistor. Again, the current is set to $20 \mathrm{~mA}$ and the students are asked to calculate the range of current values through the diode if the voltage source were to change its value by $\pm 5 \%$ around the nominal. By comparing the spread in currents, both in terms of their absolute values and their uniformity around the nominal, students develop an appreciation for the difference between linear and nonlinear models and how vital the resistor is to protecting the LED.

In another related in-class activity, students consult the datasheets for the LED and PT to determine voltage and current ranges for each component's proper use. Perhaps the most sophisticated concept approached in these activities is proper biasing of the PT. Prior to Fall 2011, the term "bias" was only used to refer to the need to power an operational amplifier. With regard to the PT, proper biasing refers to placing the device's operating point in the appropriate range so that the PT acts like a nearly ideal (dependent) current source. Again, prior to the advent of the project circuit, the instructor would briefly discuss the current-voltage relationship for an ideal current source, but no specific attention was drawn to a meaningful example. In the associated lab portion of the PPG activities, through both calculation and experiment, students determine suitable values for resistors $\mathrm{R}_{1}$ and $\mathrm{R}_{2}$ of the PPG circuit. In addition, students develop a dependent source model for the PT using the current through the LED as a controlling variable. The model requires students to determine a gain that relates the current through the PT to the current through the LED and to use a simple linear regression to address the quality of the model in fitting the experimental data. This new attention to the application of linear versus non-linear components and dependent sources concepts are examples of the intent of the project circuit philosophy, namely to take concepts from the course and have students meaningfully investigate their application.

In the Fall of 2011, eight of the approximately forty lecture periods were devoted to in-class PPG-related activities, whereas only five lectures were originally planned for the PPG circuit. The additional three lecture periods were devoted to the PPG circuit based on the necessary time that was required to adequately cover the material presented in the project circuit workbook, 
which collects both the prelab activities and the lab exercises. It should be mentioned that prior to Fall 2011 the materials had been "test-driven" by students who had just completed the circuits course to help ensure that the degree of difficulty was reasonable. However, the materials were not tested in a classroom setting and strict accounting of the time required for the students to complete the activities was not recorded. A common concern of instructors considering implementing active learning exercises within the confines of lecture time is whether the amount of content covered in the course will necessarily diminish due to the loss of lecture time. This is of particular concern in classes that are prerequisites for much of the curriculum to follow, as is the case of the course considered in this paper. Cooper et al. [3] found through interviews that, "About two-thirds of the faculty members we interviewed said that they covered fewer topics in class when they used group work, but that students learned and retained more of the 'big ideas' that they chose to address relative to using lecture formats." Such a sentiment served as inspiration for the instructor to try the project circuit concept in spite of some concern with regard to losing previously-covered lecture material. In the Fall 2011 offering of EELE 201, some previously-given lecture material was indeed cut. For the most part, the removed material was deemed, by the instructor, to be the most esoteric and least well-received material in the course with the exception of approximately two lectures that were lost in covering material related to examples of ideal transformers.

Table II: Course Concepts As Related To The PPG Circuit

\begin{tabular}{|c|c|}
\hline PPG Element / Related Tasks & Course Topics \\
\hline $\begin{array}{c}\text { LED and } R_{1} \text { circuit loop design: } \\
\text { Students choose } \mathrm{R}_{1} \text { value to ensure safe } \\
\text { operation of LED and maintain specified } \\
\text { battery life }\end{array}$ & $\begin{array}{c}\text { Linear and nonlinear models, Kirchhoff's and } \\
\text { Ohm's laws, power calculations }\end{array}$ \\
\hline $\begin{array}{c}R_{2} \text { and PT loop: } \\
\begin{array}{c}\text { Students must choose } \mathrm{R}_{2} \text { value that ensures } \\
\text { that PT will act as an approximately ideal } \\
\text { dependent source and provide significant gain }\end{array}\end{array}$ & $\begin{array}{c}\text { Ideal dependent source and its range of } \\
\text { operation, Kirchhoff's and Ohm's laws }\end{array}$ \\
\hline $\begin{array}{c}\text { Virtual ground circuit: } \\
\text { Students become aware of limits of output } \\
\text { signal swing when operating with a single } \\
\text { battery and must design virtual ground } \\
\text { circuitry (choose } \mathrm{R}_{5} \text { and } \mathrm{R}_{6} \text { ) to center signal } \\
\text { swing }\end{array}$ & $\begin{array}{c}\text { Ideal op amp analysis, voltage saturation in op } \\
\text { amps, power calculations including op amp } \\
\text { supply current }\end{array}$ \\
\hline $\begin{array}{c}\text { Noninverting operational amplifier circuit: } \\
\text { With knowledge of the approximate signal at } \\
\text { the op amp's input and the necessary voltage to } \\
\text { activate the audible indicator (not shown), } \\
\text { students settle on gain and thus values for } \mathrm{R}_{3} \\
\text { and } \mathrm{R}_{\mathrm{F}} \text {. }\end{array}$ & $\begin{array}{c}\text { Ideal op amp analysis, superposition when } \\
\text { considering existence of } \mathrm{V}_{\mathrm{REF}}\end{array}$ \\
\hline $\begin{array}{c}\text { Circuit time constant: } \\
\text { Students must consider values of C and } \mathrm{R}_{4} \text {, and } \\
\text { perhaps reconsider } \mathrm{R}_{2} \text {, when settling on time } \\
\text { constant }\end{array}$ & $\begin{array}{c}\text { Thévenin equivalent circuit (seen by } \\
\text { capacitor), complete response of first-order } \\
\text { circuit, static offsets in op amps }\end{array}$ \\
\hline
\end{tabular}


Approximately seven and a half lab periods were devoted to the PPG-related activities whereas only five were planned with the extra lab periods granted to allow all the students to finish the related activities. The additional lab periods required for the PPG-related materials necessitated the removal of one previously-planned lab activity and a second laboratory quiz. Initially, the instructor was not overly concerned with removing a lab devoted to sinusoidal steady state analysis as a very similar lab is given in the follow-on course, EELE 203 - Circuits 2. In retrospect, the loss of this particular lab exercise may in part explain why the Fall 2011 EELE 201 cohort scored somewhat lower on a particular part of one of the essay exams. This point is discussed more fully later in the paper. Due to the additional time required by the PPG-related material, the second project circuit, an audio amplifier was not deployed.

\section{Learning Outcomes Survey Data}

The project evaluator and the PI collaborated on an online pre- and post- course survey for the Fall 2010 traditional version of the course. The project plan and surveys were approved by the Montana State University Institutional Review Board. The surveys were developed and administered in the web learning platform Desire 2 Learn (D2L). The survey asked students to rate their knowledge of a host of course learning outcomes, including four newly developed outcomes designed to test students' deeper learning of course content. There were a total of 42 learning outcomes in the Fall 2010 survey and 44 in the Fall 2011 survey; however, only a set of 9 (including 4 "deeper learning” outcomes) were of interest in this study. Students responded via a 5-point agreement scale, with the lower end of the scale anchored with "Strongly Disagree" and the upper end of the scale anchored with "Strongly Agree." The survey also asked students to respond to questions regarding learning style, including lecture, the textbook, class discussion, and peer group studying. Prior to taking the pre-survey, students were informed about the project with an introductory paragraph on the survey and asked to agree or disagree to participate-in other words, participation was optional. All but two students opted to participate. After the survey data were collected at the end of the course, the project evaluator conducted two-sample t-tests on all of the survey questions to determine whether the students' perception of learning was higher at the end of the semester than it was at the beginning. Within-subjects tests could not be used because of the anonymity of the data. The two-sample t-tests produced the following results on the outcomes questions of interest and the learning style questions:

- All questions showed a significant difference $(p \leq .05)$ between pre- and post-surveys (in a positive direction).

In Fall 2011, the survey was administered again at the beginning and at the end of the semester. In order to determine if the two samples of students (Fall 2010 and Fall 2011) were similar, presurvey results from the two groups were compared. Fall 2011 responses were significantly lower than Fall 2010 responses $(p \leq .05)$ for one of the learning outcomes questions:

- I am able to solve for voltages and currents in circuits that contain dependent sources.

Because this particular outcome is not addressed in the prerequisite to EELE 201, it is not surprising that students in any semester do not have knowledge of the outcome coming in to EELE 201. 
Two-sample t-tests comparing the Fall 2011 student responses on the pre-survey to the responses on the post-survey produced significant results (post-survey responses being higher) for all outcomes questions of interest $(p \leq .05)$.

All pre- and post- survey results (average survey responses) are shown in Table III below:

\section{Table III. Pre- and Post-Survey Results (Means) for Fall 2010 and Fall 2011 Learning} Outcomes of Interest

\begin{tabular}{|c|c|c|c|c|}
\hline 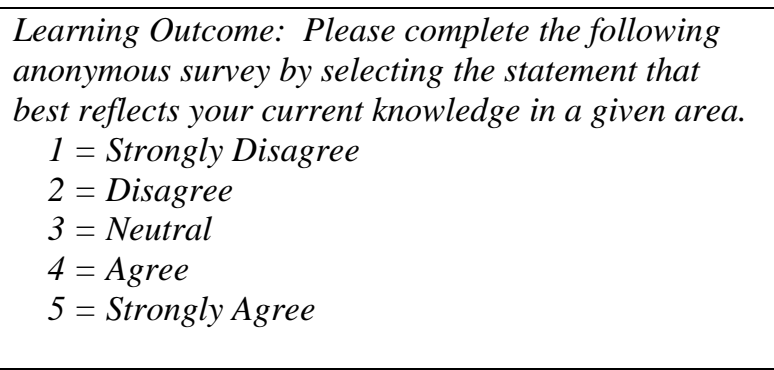 & $\begin{array}{c}\text { Pre-Survey } \\
\text { Mean F2010 } \\
n=47\end{array}$ & $\begin{array}{l}\text { Post-Survey } \\
\text { Mean F2010 } \\
\quad n=33\end{array}$ & $\begin{array}{c}\text { Pre-Survey } \\
\text { Mean F2011 } \\
\quad n=48\end{array}$ & $\begin{array}{c}\text { Post-Survey } \\
\text { Mean F2011 } \\
\quad n=41\end{array}$ \\
\hline $\begin{array}{l}\text { I am able to able to apply the "Node Voltage } \\
\text { Analysis" technique to solve circuits containing } \\
\text { resistors, capacitors and inductors. }\end{array}$ & 3.06 & 4.61 & 3.10 & 4.39 \\
\hline $\begin{array}{l}\text { Assuming ideal operational amplifier (op-amp) } \\
\text { operation, I am able to analyze circuits containing } \\
\text { op-amps. }\end{array}$ & 2.17 & 4.36 & 2.04 & 4.17 \\
\hline $\begin{array}{l}\text { I am able to articulate what is meant by a } \\
\text { "dependent" source and identify what such a source } \\
\text { typically models. }\end{array}$ & 2.79 & 4.67 & 2.40 & 3.90 \\
\hline $\begin{array}{l}\text { I am able to solve for voltages and currents in circuits } \\
\text { that contain dependent sources. }\end{array}$ & 3.09 & 4.24 & 2.54 & 3.90 \\
\hline $\begin{array}{l}\text { I am able to determine the complete response of } \\
\text { arbitrary first order RL and RC circuits. }\end{array}$ & 2.09 & 4.39 & 1.90 & 3.98 \\
\hline $\begin{array}{l}\text { I am able to break down a circuit containing } \\
\text { elements such as operational amplifiers, resistors, } \\
\text { capacitors, inductors and dependent sources into } \\
\text { sub-circuits to facilitate analysis of the complete } \\
\text { circuit. }\end{array}$ & 2.49 & 4.27 & 2.58 & 3.78 \\
\hline $\begin{array}{l}\text { I am able to develop and describe in writing an } \\
\text { outline of an approach to analyzing an electric } \\
\text { circuit which contains multiple and varied circuit } \\
\text { elements including operational amplifiers, resistors, } \\
\text { capacitors, inductors and dependent sources. }\end{array}$ & 2.34 & 3.97 & 2.23 & 3.63 \\
\hline $\begin{array}{l}\text { I am able to identify component limitations (e.g. } \\
\text { saturation, slew rate, power rating, battery life) that } \\
\text { may be important in a given circuit and suggest } \\
\text { means to design the circuit such that component } \\
\text { limitations are not exceeded. }\end{array}$ & 2.12 & 3.85 & 2.06 & 3.29 \\
\hline $\begin{array}{l}\text { I am able to describe the relationship between the } \\
\text { time-domain and frequency domain descriptions of } \\
\text { first-order circuits with either sinusoidal or constant } \\
\text { inputs. }\end{array}$ & 2.13 & 4.49 & 2.06 & 4.17 \\
\hline
\end{tabular}

In regard to the learning style survey questions, the Fall 2010 students were significantly more likely to respond positively at the end of the semester about the textbook and working with classmates $(p \leq .05)$. There were no differences for lectures, homework, or labs (see Table IV). 
The Fall 2011 responses to the learning style questions showed that students were significantly less positive at the end of the course $(p \leq .05)$ toward the following approaches to learning the course material:

- Working through homework

- Laboratory exercises

Table IV. Learning Mode Pre- and Post-Survey Results (Means) for Fall 2010 and Fall 2011

\begin{tabular}{|c|c|c|c|c|}
\hline $\begin{array}{l}\text { Learning Mode: Please rate the following items with } \\
\text { regard to how effective you found them in helping } \\
\text { you learn the course content. A score of "1" } \\
\text { indicates the item was of little to no help, whereas a } \\
\text { score of 5 indicates the item was extremely helpful }\end{array}$ & $\begin{array}{c}\text { Pre-Survey F2010 } \\
n=48\end{array}$ & $\begin{array}{c}\text { Post-Survey } \\
\text { Mean F2010 } \\
n=33\end{array}$ & $\begin{array}{c}\text { Pre-Survey } \\
\text { Mean F2011 } \\
n=49\end{array}$ & $\begin{array}{c}\text { Post-Survey } \\
\text { Mean F2011 } \\
n=41\end{array}$ \\
\hline$\bullet \quad$ Lectures & 4.06 & 4.00 & 4.27 & 4.42 \\
\hline$\bullet \quad$ Reading the course text & 2.77 & 3.27 & 3.29 & 3.24 \\
\hline - Working through the homework & 4.04 & 4.33 & 4.56 & 4.12 \\
\hline - Working with classmates & 3.42 & 3.97 & 3.92 & 4.24 \\
\hline - Laboratory exercises & 3.85 & 3.76 & 4.33 & 3.73 \\
\hline
\end{tabular}

The homework assignments were not changed from Fall 2010 to Fall 2011, so students might have found the homework less meaningful than the class sessions in Fall 2011, considering the changes in the approach in class. In regard to the laboratory exercises, the PPG circuit-related activities are geared toward showing students how the course concepts are applied to the design and analysis of practical circuits. Because the survey question asks students to rate the various approaches in regard to how they help learning, students might have recognized that they have (hopefully) already learned the concept prior to the lab. As revealed from some of their comments, some students had difficulty in seeing how the PPG circuit related to the class concepts. As discussed later in the paper, changes have been made to the PPG circuit materials to make more explicit the connections between pre-lab activities and the lab activities themselves, which could help students tie the classroom concepts and the lab activities together.

Even though there were no significant differences in the student responses to lectures as a learning mode, the mean score for lectures went down slightly in Fall 2010 and went up in Fall 2011, which could indicate that the new in-class approach is helping students learn.

\section{Essay Test Data}

The Essay Tests I and II were designed to correlate with the outcomes, particularly the four newly developed deeper learning outcomes. The project PI and the project evaluator collaborated on an initial scoring rubric for the tests; the rubric had a holistic scoring range of 1 to 5. A teaching assistant for the course graded both the Fall 2010 and Fall 2011 essays exams to help ensure consistency. The rubric was somewhat modified by the teaching assistant, with agreement from the PI and project evaluator, based on an overall examination at the wealth of potential responses offered by the students that did not sufficiently align with the initial rubric. Due to their unconventional nature, the essay test grades were not counted toward the students' final grade. Students were informed that as long as they gave reasonable effort in completing the 
essays exams, their scores on the exams would not hurt their overall grade. To give a general flavor for the essay exams a few of the questions follow.

In Essay exam 1, students were given a circuit schematic showing an op amp in a non-inverting amplifier configuration, fed with a sinusoidal voltage source through a parallel LC resonant circuit. During one lecture period, a series RLC circuit was briefly discussed when introducing the concept of the phasor diagram, but the topic of resonant circuits is actually reserved for EELE 203 - Circuits 2. Among other questions, students were asked:

(1) Identify all the potential sources of frequency dependent behavior in the circuit and briefly explain each.

(2) You are to solve the problem in the frequency domain, using phasors - what is the justification and what are the assumptions in solving the problem in this manner?

(3) Sketch the magnitude of the output voltage as a function of the input frequency and explain the rationale for your sketch. HINT: Consider three key frequency ranges: very low frequencies, very high frequencies and frequencies around resonance. If you have forgotten the equation for resonance, come see the instructor. While you may certainly use equations, you will likely be able to reason out at least part of the sketch without resorting to a full evaluation of the output voltage equation. Question 4 asks you to develop the expression.

Later in Essay Test 1, students were to speculate on how they might approach solving the problem if the source were a unit step instead of a sinusoid. Essay Test 2 asked students to choose between two potential circuits that would allow one to amplify a pulsing current input that had a somewhat unpredictable, but much larger, DC offset. After explaining the rationale for their selection, the students would hand in the initial part of Essay Test 2. The second part of the exam asked students to outline a procedure to analyze the more appropriate circuit for the application. Table $\mathrm{V}$ shows the average scores (on the rubric scale of 1-5, with a score of 5 indicating a fully correct/complete response) for each part of Essay Test 1 for Fall 2010 and Fall 2011.

Table V. Essay Test 1 Scores Fall 2010 and Fall 2011

\begin{tabular}{|l|c|c|}
\hline Test Section & $\begin{array}{c}\text { Mean Score } \\
2010 \\
n=37\end{array}$ & $\begin{array}{c}\text { Mean Score } \\
2011 \\
n=42\end{array}$ \\
\hline Part 1 & 2.86 & 2.64 \\
\hline Part 2 & 1.03 & 1.26 \\
\hline Part 3 & 1.84 & 1.67 \\
\hline Part 4 & 1.78 & 1.07 \\
\hline Part 5 & 1.70 & 1.45 \\
\hline
\end{tabular}

In general, the scores are reasonably similar for the two cohorts. However, the scores were significantly lower $(p \leq .05)$ in Fall 2011 for part 4 of Essay Test 1. A potential explanation of the drop in performance on this part of Essay Test 1 in Fall 2011 stems from the fact that, due to 
time constraints in Fall 2011, a lab was removed from the course that included a mathematical manipulation directly tied to part 4 of Essay Test 1 . Initially, the instructor was not overly concerned with removing this lab devoted to sinusoidal steady state analysis as a very similar lab is given in the follow-on course, EELE 203 - Circuits 2. In retrospect, the loss of this particular lab exercise may in part explain why the Fall 2011 EELE 201 cohort scored lower on this particular part of the Essay Test 1. As discussed later in the paper, changes have been made to delivery of the project circuit materials to recover a modified version of the lost lab activities.

Table VI . Essay Test 2 Scores Fall 2010 and Fall 2011

\begin{tabular}{|l|c|c|}
\hline Test Question & $\begin{array}{c}\text { Mean Score } \\
2010 \\
\mathrm{n}=34\end{array}$ & $\begin{array}{c}\text { Mean Score } \\
2011 \\
\mathrm{n}=43\end{array}$ \\
\hline 1 & .85 & 1.76 \\
\hline 2 & 2.12 & 3.19 \\
\hline 3 & .85 & 1.33 \\
\hline 4 & .88 & .88 \\
\hline 5 & 2.47 & 3.48 \\
\hline 6 & 1.09 & 1.09 \\
\hline 7 & .21 & .24 \\
\hline 8 & .44 & .38 \\
\hline 9 & .88 & 1.29 \\
\hline 10 & .27 & .36 \\
\hline Total & 10.06 & 14.00 \\
\hline
\end{tabular}

Table VII. Essay Test 2 Scores Fall 2010 and Fall 2011 (modified)

\begin{tabular}{|l|c|c|}
\hline Test Question & $\begin{array}{c}\text { Mean Score } \\
2010 \\
\mathrm{n}=33\end{array}$ & $\begin{array}{c}\text { Mean Score } \\
2011 \\
\mathrm{n}=42\end{array}$ \\
\hline 1 & .88 & 1.76 \\
\hline 2 & 2.18 & 3.19 \\
\hline 3 & .88 & 1.33 \\
\hline 4 & .85 & .90 \\
\hline 5 & 2.52 & 3.50 \\
\hline 6 & 1.09 & 1.05 \\
\hline 7 & .21 & .24 \\
\hline 8 & .45 & .38 \\
\hline 9 & .91 & 1.29 \\
\hline 10 & .27 & .36 \\
\hline Total & 10.24 & 14.00 \\
\hline
\end{tabular}

Tables VI and VII show the Essay Test 2 scores for Fall 2010 and Fall 2011. Table VII is identical to Table VI save for the fact that the scores for students who obviously did not actually attempt the essay questions (little or nothing was written) have been removed. As can be seen from examination of Table VI, the Fall 2011 scores were significantly higher for questions 1, 2, and 5; in addition, the total essay quiz score (the average) was significantly higher in Fall 2011. When removing the scores of the few students not actively participating in the exam, scores were 
significantly higher in Fall 2011 for questions 1 and 5; in addition, the total essay quiz score average for Fall 2011 was significantly higher than Fall 2010 as well.

Question 1 of Essay Test 2 asked students to select, and to justify their selection of the appropriate choice of two competing circuits for a given application. The appropriate circuit for the application was the one that effectively separated the DC and time varying components of the input signal such that only the small time varying component would be amplified by an operational amplifier. Question 5 asked students to derive the relatively simple expression for the gain of the amplification stage. Overall, Essay Test 1 tends to probe the final outcome listed in Table III whereas Essay Test 2 probes the other three deeper outcomes (the remaining outcomes that are italicized in Table 3). Based on these initial results, inclusion of the project circuit seems to have a positive impact on helping students in terms of the deeper learning outcomes. This point is to be assessed further in subsequent offerings of the course.

\section{Classroom Observations}

As an additional measure of student engagement prior to the instructional intervention and after the instructional intervention, the project evaluator conducted two classroom observations in each of the semesters (Fall 2010 and Fall 2011). The observations were timed so that the same material was being covered. During each observation, the evaluator recorded, at two-minute intervals, what the instructor was doing and what the students were doing. The major classroom activity for all of the observations was students working in groups; however, there were marked differences in the student engagement between Fall 2010 and Fall 2011. During the Fall 2010 class periods, several students worked on the group activity individually, and in some of the groups, there was little discussion; in other words, the students were sitting in groups but not actually working collectively. In addition, the observer noted that a few students were texting or otherwise occupied. Several students left the classroom prior to the end of the class session. During the Fall 2011 observations, students were anxious to get to work in their groups-no one worked individually, as far as the observer could tell. There was much discussion and chatter, all apparently related to the problem at hand. Students raised their hands frequently with questions, which were addressed either by the instructor or the TA; however, the student questions weren't answered outright-in a true inquiry-based approach, the instructor and TA would ask the student who had the question additional questions or offer other thoughts in order to direct the student to answer the question him or herself. No students were engaged in texting or other unrelated activities, and no students left class before the class period was over. In fact, students were still talking animatedly in their groups when the bell rang.

\section{Going Forward with the PPG Project Circuit}

Based on the preliminary results for the initial implementation of the PPG circuit concept in the Fall 2011 offering of EELE 201, changes have been made to both the in-class activities and to the lab explorations for deployment in the spring 2012 offering of the course. The changes have been made to: (1) provide a clearer connection between standard course content and the PPG project circuit materials, (2) streamline the activities so the focus is more precise allowing students to complete the exercises in a timely fashion, and (3) ensure students are better prepared upon entering the lab to complete the activities for the given lab period. Two of the key changes 
have been to: (1) convert some of the in-class activities, particularly those that stress more calculation rather than concept and that are most directly related to having students prepared to carry out the experiments, to homework assignments that are due prior to the lab and, (2) breaking the last set of lab activities into two distinct sets of experiments. The first set of such experiments will draw a much closer connection between the concepts of first-order circuits and time constants to the PPG circuit by exploring the excitation of the amplification stage to an ideal pulse train and the second set will simply be a demonstration of the full PPG circuit with the audible indicator. In the Fall 2011 offering, the final lab combined both these tasks, but did an inadequate job in terms of connecting the time constant concept to the PPG circuit.

There are some interesting unanswered questions that seem worth exploring. For example,

Does challenging a class with a complicated problem or activity give students a more realistic impression of their actual competence in given course outcomes and can such an effect be taken into account when reviewing student perception scores? Does a better awareness of actual competence encourage or discourage the typical student to persist in the discipline? What are the most effective means to probe deeper knowledge? What is the effect of inclusion of the project circuit concept on student retention and performance in subsequent courses?

\section{Conclusions}

A project circuit concept has been deployed in the Fall 2011 offering of EELE 201 - Circuits 1 at Montana State University in an effort to inspire the interest of students to master the somewhat mundane concepts in a typical introductory circuit analysis course through offering students a chance to apply their blossoming knowledge to a practical electric circuit. The results of this initial attempt of having students design and construct a photoplethysmograph (PPG) circuit in terms of both student perception and student mastery of the course content was found to be, generally speaking, positive. A few of the positive and negative experiences with the project circuit materials are captured below:

- From a student: This lab has shown me how the things we are learning can be applied to something that has a real world application, and has sparked my interest in the field more than it had been before.

- From a staff person in the ECE department: I rode down the elevator with one of your 201 students. He was carrying a breadboard with a heart rate sensor that he had built in class. I asked him what it was. When we got off the elevator he explained to me how it worked and what all the parts were and did. He was very proud of it. He was going to attach a 9 volt battery to it and take it home to show his family. He's hooked.

- From a student: In the PPG lab, it was often unclear what the point of certain labs were or what we were supposed to learn or take away. It would be nice to have labs that had a more specific purpose; that were designed to teach us a certain thing and told us what they were designed to teach us.

Due to both the challenging nature of the PPG circuit-related materials and the student-centered approach (inquiry-based and active learning) taken in studying them, it was fully expected by the 
instructor that the project circuit materials might engender strong positive feelings in some students and equally strong negative feelings in others. Indeed, student resistance to studentcentered instruction techniques has been noted elsewhere, for example [4] and [5]. That being said, the comment regarding the fact that the PPG materials potentially left the student uncertain as to the take-away points is being taken very seriously. Despite the somewhat uneven initial experience, rather than abandoning the concept, steps are underway to modify the materials to improve the overall experience for students. Even if the changes to the materials prove effective, there are two key features that must remain for the project circuit approach to prove sustainable. First, there must be an instructor willing to use the student-centered approach, which even though shown to be successful in various disciplines over many years of research, is still considered a suspect and risky approach by many college instructors. Second, there must be very skilled lab assistants who both understand the project circuit and are able to help students make their way toward their own understanding.

\section{Acknowledgements}

Partial support for this work was provided by the National Science Foundation's Course, Curriculum, and Laboratory Improvement (CCLI) program under Award No. 0941660. Any opinions, findings, and conclusions or recommendations expressed in this material are those of the authors and do not necessarily reflect the views of the National Science Foundation.

\section{Bibliography}

1. Robert C. Maher, James Becker, Tia Sharpe, James Peterson and Bradford A. Towle, "Development and Implementation of a Robot-based Freshman Engineering Course,” Proceedings of the 2005 American Society for Engineering Education Annual Conference and Exposition.

2. Richard C. Dorf and James A. Svoboda, Introduction To Electric Circuits, $8^{\text {th }}$ edition, John Wiley and Sons, Inc. 2010.

3. James L. Cooper, Jean MacGregor, Karl A. Smith and Pamela Robinson, "Implementing Small-Group Instruction: Insights from Successful Practitioners,” New Directions in Teaching and Learning, no. 81, pp. 63-75, Spring 2000.

4. Richard M. Felder and Rebecca Brent, "Navigating the Bumpy Road to Student-Centered Instruction,” College Teaching, Vol. 44, No. 2, Spring 1996.

5. Michael Prince and Richard Felder, "The Many Faces of Inductive Teaching and Learning,” Journal of College Science Teaching, March 2007. 